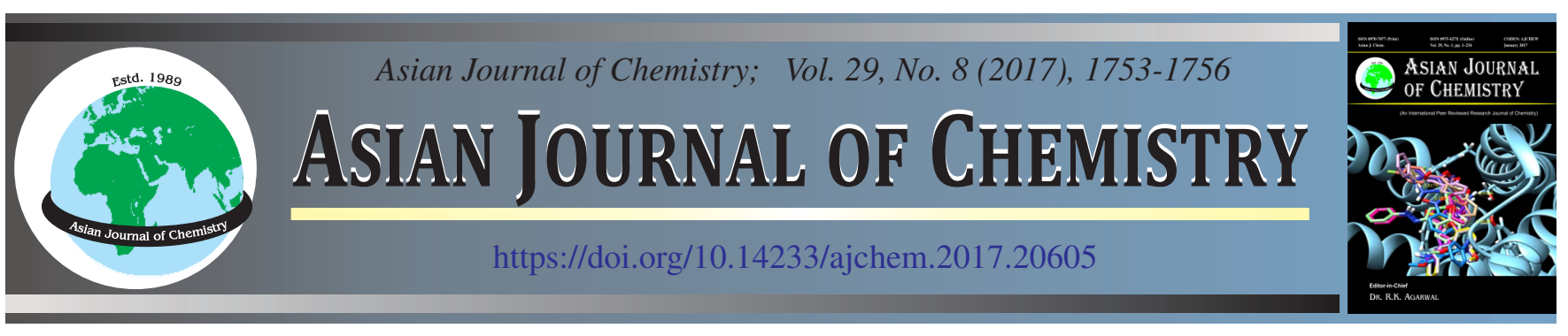

\title{
Mycotoxins Survey in Imported Wheat Commodity During 2016 in Albania
}

\author{
A. SHTËMBARI ${ }^{*}$ and D. TopI
}

Faculty of Natural Sciences, University of Tirana, Blvd. Zogu 1, No. 25, Tirana 1009, Albania

*Corresponding author: E-mail: aferditashtembari@live.com

\begin{abstract}
In this study, we have analyzed mycotoxins contamination in wheat commodity, both soft and durum, imported during first half of 2016 in Albania. Random samples $(n=35)$ were taken in from three main flour mills of Albania. The objective of this study was to access the risk exposure posed to humans and animals to different untargeted mycotoxins. The samples were analyzed for main mycotoxins: AFB1, AFB2, AFG1 and AFG2, zearalenon (ZEN), deoxynivalenol (DON), FB1, FB2 and Ochratoxin A (OTA) contamination by LC-MS/MS. Data revealed a normal situation regarding to the contamination to the imported wheat commodities. So, was found only one sample contaminated by DON, which do not exceeded the maximum limit as defined by National and European Regulations. In conclusion, we have considered that the risk human exposure to the wheat samples imported in during the period is low.
\end{abstract}

Keywords: Mycotoxins, Wheat, Aflatoxins, Zearalenon, Deoxynivalenol, Ochratoxin A, Albania.

\section{INTRODUCTION}

Cereal crops cultivation constitute main group in domestic agriculture of Albania. The maize is mainly used as feed commodity, while the wheat is used mainly as food for humans. Despite huge arable land of the country is covered by cereals, it is considered that over $50 \%$ of country needs to wheat and wheat products are covered by import. Because of the main role of wheat and its flour products in the diet of humansits can play a very important role in endangering human health in case of contamination and foodborne diseases. In the farm and the warehouse, wheat can be invaded by different microorganisms, especially fungi [1,2].

Mycotoxins are toxic secondary metabolites produced by certain fungi that can infect various agricultural commodities in the field and/or during their storage. Mycotoxins have various acute and chronic effects on humans and animals. The most important ones associated with human and animal diseases, include aflatoxins, Fusarium toxins (fumonisins, trichothecenes and zearalenone), ochratoxin A, citrinin and ergot alkaloids.

The major classes of mycotoxins are aflatoxins (AFs) produced by Aspergillus fungi, mainly A. flavus and A. parasiticus. The four major aflatoxins are called $\mathrm{B}_{1}$ (AFB1), $\mathrm{B}_{2}$ (AFB2), $\mathrm{G}_{1}$ (AFG1) and $\mathrm{G}_{2}$ (AFG2) based on their fluorescence under UV light (blue or green) and relative chromatographic mobility during thin-layer chromatography [3]. The diseases caused by aflatoxin consumption are loosely called aflatoxicoses.
Acute aflatoxicosis may results in death; while chronic exposure may results in cancer, immune suppression and other "slow" pathological conditions [4]. AFB1 is the most known potential hepatocarcinogenic in mammals and it is classified by the International Agency of Research on Cancer (IARC) as Group 1 carcinogen [5].

Ochratoxin A (OTA) is produced by Aspergillus ochraceus and Penicillium verrucosum species. Exposure to OTA has been associated with distinct renal diseases in humans endemic in the Balkans (in Bulgaria and former-Yugoslavia), referred to as Balkan Endemic Nephropathy (BEN) [6]. Ochratoxin A is a nephrotoxin, affecting all tested animal species, though effects in man have been difficult to establish unequivocally. It is listed as a probable human carcinogen (Class 2B) [7].

Zearalenon (ZEN) is aoestrogenic mycotoxin that can be produced by several field fungi including Fusarium graminearum (Gibberellazeae), F. culmorum, F. cerealis, F. equiseti and $F$. semitectum [3]. The critical effects of ZEN result from its potent estrogenic activity, considered as a possible causative agent in the outbreaks of precocious pubertal changes in the young children. The International Agency for Research on Cancer (IARC) has categorized ZEN as a Class 2A carcinogen [8].

Deoxynivalenol (DON) is a natural-occurring mycotoxin mainly produced by Fusarium graminearum [9]. It is also known as vomitoxin due to its strong emetic effects after consumption, because it is transported into the brain, where it runs dopaminergic receptors. The emetic effects of this mycotoxin 
were firstly described in Japanese men consuming mouldy barley containing Fusarium fungi in 1972 [10].

In order to protect public health from this hazard, Commission Regulation (EC) setting maximum levels $(\mu \mathrm{g} / \mathrm{kg}$ ) for certain mycotoxins in foodstuffs (Table-1). Maximum levels should be set at a strict level which is reasonably achievable by following good agricultural, fishery and manufacturing practices and taking into account the risk related to the consumption of the food [11]. The current legislation about mycotoxins prevailing in Albania came into force in 2010 and it is same with European legislations.

Cereal grains contaminated with mycotoxins represent a public health problem due to the high toxicity of these substances and also because they remain partially stable during the industrial processes when manufacturing derived products $[12,13]$. The milling of the wheat can minimize mycotoxin concentrations in the fraction used for human consumption as these toxins are redistributed mainly in the bran, which is predominately used for animal feed [14,15].

Wheat and wheat products are the basis of the food in Albania, therefore the food and feed safety issue (especially wheat commodity), recently has taken an important focus. In Albania, there are few studies concerning the occurrence of mycotoxins in wheat and wheat products. This study aimed to determine the levels of aflatoxins (B1, B2, G1 and G2), ZEN, DON, in the wheat samples imported in Albania during 2016.

\section{EXPERIMENTAL}

Mycotoxins standards (AFB1, AFB2, AFG1 AFG2, DON, ZEN, FB1 and FB2) were purchased from Romer (Union, Mo, USA). Standard solutions were prepared in acetonitrile. Acetonitrile, methanol, acetic acid (Sigma-Aldrich, Steinheim, Germany) and ammonium acetate (Merck, Darmstadt, Germany) were of p.a. or LC-MS grade purity. Deionized water was prepared using a Milli-Q system (Millipore, Bedford, MA, USA).

Sample collection: In the study, 40 representative imported soft and durum wheat samples, were collected directly to mills during the spring. The wheat samples were originated by Russia, according to the accompanying certificate of the commodity. The sampling procedure was carried out according to Commission Regulation (EC) No 401/2006 on sample collection for bulk commodities [16].

Mycotoxin analysis: Simultaneous determination of mycotoxins (AFB1, AFB2, AFG1, AFG2, DON, ZEN, FB1 and FB2), consists on the mycotoxins' extraction from ground cereal samples with the acetonitrile-deionized water mixture and further determination by liquid chromatography-tandem mass spectrometry (LC-MS/MS). Sample preparation and the determination of mycotoxins was based on analytical procedures described elsewhere [17,18]. An amount of $20 \mathrm{~g}$ grounded sample was shaken with $100 \mathrm{~mL}$ of acetonitrile-deionized water mixture (80:20) for $1 \mathrm{~h}$ period using a linear shaker IKA HS 501 digital (IKA Labortechnik, Staufen, Germany). A volume of $4 \mathrm{~mL}$ pre-filtered extract was pipetted into a vial and further preceded under vacuum evaporation to dryness using the system Syncore Polyvap (Büchi, Flawil, Switzerland). The residue was reconstituted with $0.5 \mathrm{~mL}$ of methanoldeionized water mixture $(80+20)$ and passed to analytical vials. Finally, a volume $20 \mu \mathrm{L}$ was injected into LC-MS/MS. The detection and quantification was performed with an UPLC system Acquity coupled to a triple-quadrupole mass spectrometer Xevo TQ MS equipped with electrospray ionization (ESI) interface (Waters, Milford, MA, USA). The chromatographic separation was performed at the column Zorbax Eclipse Plus C18 Rapid Resolution HD, $2.1 \times 100$ mm, 1.8 $\mu \mathrm{m}$ (Agilent). The mobile phase consisted of two components mixed in gradient mode. Component A was deionized water and component $\mathrm{B}$ was methanol, both containing $0.5 \%$ acetic acid and $0.25 \mathrm{mM}$ ammonium acetate. For each mycotoxin the precursor ion and two product ions (a quantifier and a qualifier ion) were tracked together with the limits of detection (LOD), limits of quantification (LOQ) and recoveries for each single mycotoxin. Data acquisition and processing was done by means of MassLynx program (Waters, Milford, MA, USA).

TABLE-1

MAXIMUM LEVELS FOR CERTAIN MYCOTOXINS IN FOODSTUFFS

\begin{tabular}{|c|c|c|c|}
\hline \multicolumn{2}{|r|}{ Foodstuffs } & \multicolumn{2}{|r|}{ Maximum levels $(\mu \mathrm{g} / \mathrm{kg})$} \\
\hline 2.1 & Aflatoxins & B1 & Sum of B1, B2, G1 and G2 \\
\hline 2.1 .6 & $\begin{array}{l}\text { All cereals and all products derived from cereals, including processed cereal products, with the } \\
\text { exception of foodstuffs listed in } 2.1 .7,2.1 .10 \text { and } 2.1 .12\end{array}$ & 2.0 & 4.0 \\
\hline 2.2 & Ochratoxin A & & \\
\hline 2.2 .1 & Unprocessed cereals & & 5.0 \\
\hline 2.2 .2 & $\begin{array}{l}\text { All products derived from unprocessed cereals, including processed cereal products and cereals } \\
\text { intended for direct human consumption with the exception of foodstuffs listed in } 2.2 .9 \text { and 2.2.10 }\end{array}$ & & 3.0 \\
\hline 2.4 & Deoxynivalenol & & \\
\hline 2.4 .2 & Unprocessed durum wheat and oats & & 1750 \\
\hline 2.4 .4 & $\begin{array}{l}\text { Cereals intended for direct human consumption, cereal flour (including maize flour, maize meal } \\
\text { and maize grits ( } 21) \text { ), bran as end product marketed for direct human consumption and germ, with } \\
\text { the exception of foodstuffs listed in } 2.4 .7\end{array}$ & & 750 \\
\hline 2.5 & Zearalenone & & \\
\hline 2.5 .1 & Unprocessed cereals other than maize & & 100 \\
\hline 2.5 .3 & $\begin{array}{l}\text { Cereals intended for direct human consumption, cereal flour, bran as end product marketed for } \\
\text { direct human consumption and germ, with the exception of foodstuffs listed in 2.5.4, 2.5.7 and } \\
\text { 2.5.8 }\end{array}$ & & 75 \\
\hline 2.6 & Fumonisins & & Sum of B1 and B2 \\
\hline 2.6 .1 & Unprocessed maize & & 2000 \\
\hline 2.6 .2 & Maize flour, maize meal, maize grits, maize germ and refined maize oil & & 1000 \\
\hline
\end{tabular}




\section{RESULTS AND DISCUSSION}

Thirty seven samples of imported wheat commodity in Albania were analyzed for the presence of mycotoxins (Aflatoxin B1, B2, G1 and G2, DON, ZEA, FB1, FB2 and OTA). The results $(\mu \mathrm{g} / \mathrm{kg})$ for mycotoxins occurrence in imported wheat commodities shown in Table-2. All the samples were positive for the mycotoxins analyzed. But was detected only one samples (23 S), contaminated with DON in the level 157 $\mu \mathrm{g} / \mathrm{kg}$, that containing higher values than maximum limits (100 $\mu \mathrm{g} / \mathrm{kg}$ ) as defined by Albanian and European legislations for cereals in general.

\section{Conclusion}

After analysis performed by HPLC in imported wheat commodity in Albania, we did not found samples containing aflatoxins (AFB1, AFB2, AFG1 and AFG2), DON, FB1, FB2 and OTA than maximum limits as defined by national and European legislations. Just one sample showed levels higher than the limit established by legislation $(100 \mu \mathrm{g} / \mathrm{kg})$ for ZEN. From this experimental work, we conclude that the risk of the wheat samples imported in Albania during 2016 is present.

Considering all the problems that causing contaminated cereals with mycotoxins in human and animal health, it is recommended to make systematic analyses, because cereals (especially wheat commodity) are the basic food of population in Albania. Being the basic food of the population, increases the possibility of exceeding the daily limits that everybody (human and animals) should consume.

\section{REFERENCES}

1. World Health Organization, Evaluation of Certain Food Additives and Contaminants, Forty-Fourth Report of The Joint FAO/WHO Expert Committee on Food Additives, WHO, Geneva (1995).

2. CAST, Mycotoxins: Risks in Plant, Animal and Human Systems, Council for Agricultural Science and Technology, Ames, Iowa, USA (2003).

3. J.W. Bennett and M. Klich, Clin. Microbiol. Rev., 16, 497 (2003); https://doi.org/10.1128/CMR.16.3.497-516.2003.

4. R.R. Paterson and N. Lima, EXS, 100, 31 (2010).

5. IARC, Off. J. Eur. Union L, 364, 5 (1993).

6. M. Peraica, B. Radic, A. Lucic and M. Pavlovic, Bull. World Health Organ., 77, 754 (1999).

7. M. Olsen, N. Jonsson, J. Magan, C. Banks, A. Fanelli and A. Rizzo, in eds.: A. D. Hocking, J. I. Pitt, R.A. Samson, and U. Thrane, Prevention of Ochratoxin A in Cereals in Europe, In: Advances in Food Mycology, Springer Science+Business Media, New York, USA. p. 375 (2006).

8. IARC, IARC Monographs on the Evaluation for Carcinogenic Risks to Humans, Some Naturally Occurring Substances, Food Items and Constituents, Heterocyclic Aromatic Amines and Mycotoxins, vol. 56 (1993).

TABLE-2

MYCOTOXINS OCCURRENCE IN IMPORTED WHEAT COMMODITIES $(\mu \mathrm{g} / \mathrm{kg})$

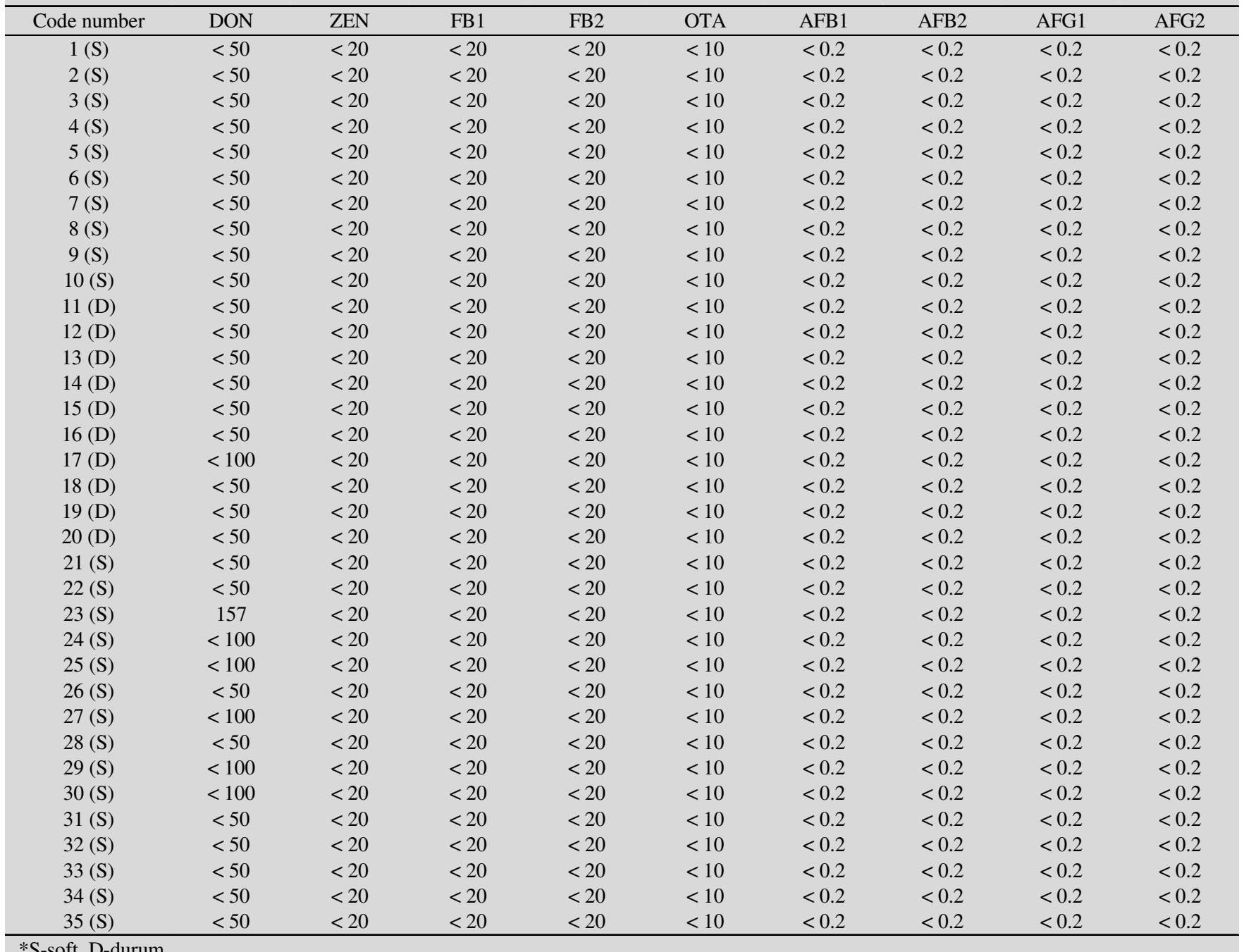


9. M. Kushiro, Int. J. Mol. Sci., 9, 2127 (2008); https://doi.org/10.3390/ijms9112127.

10. Y. Ueno, ISI Atlas Sci. Pharmacol., 2, 121 (1988)

11. European Commission, Off. J. Eur. Union L, vol. 364 (2006).

12. L.B. Bullerman and A. Bianchini, Int. J. Food Microbiol., 119, 140 (2007); https://doi.org/10.1016/j.ijfoodmicro.2007.07.035.

13. I. Giménez, M. Herrera, J. Escobar, E. Ferruz, S. Lorán, A. Herrera and A. Ariño, Food Control, 34, 268 (2013); https://doi.org/10.1016/j.foodcont.2013.04.033.

14. M. Herrera, T. Juan, G. Estopaña and A. Ariño, J. Food Nutr. Res., 48 , 92 (2009).
15. F. Cheli, L. Pinotti, L. Rossi and V. Dell'Orto, LWT-Food Sci. Technol., 54, 307 (2013); https://doi.org/10.1016/j.lwt.2013.05.040.

16. European Commission, Off. J. Eur. Union L, 70, 12 (2006).

17. F. Driehuis, M.C. Spanjer, J.M. Scholten and M.C. Te Giffel, Food Addit. Contam. B, 1, 41 (2008); https://doi.org/10.1080/19393210802236927.

18. V.M.T. Lattanzio, S.D. Gatta, M. Suman and A.Visconti, Rapid Commun Mass Spectrom., 25, 1869 (2011); https://doi.org/10.1002/rcm.5047. 